\title{
Diagnostic investigations of PLA2G16 and CDH11 expression levels as independent prognostic markers of human osteosarcoma
}

\author{
Salman Azarsina ${ }^{1}$, Babak Otoukesh², Afshin Taheriazam³ ${ }^{3}$, Maria Kaghazian4, Bahram Boddouhi ${ }^{2}$, \\ Emad Yahaghi5, Peyman Kaghazian ${ }^{6}$
}

\author{
${ }^{1}$ Department of Orthopedics, Alborz University of Medical Sciences, Karaj, Iran \\ 2Department of Orthopedic Surgery, Rasoul-e-Akram Hospital, Iran University \\ of Medical Science, Tehran, Iran \\ ${ }^{3}$ Department of Orthopedic Surgery, Tehran Medical Sciences Branch, Islamic Azad \\ University, Tehran, Iran \\ ${ }^{4}$ Department of Biology, Jundishapur University of Medical Sciences, Ahvaz, Iran \\ ${ }^{5}$ Department of Molecular Biology, Baqiyatallah University of Medical Sciences, \\ Tehran, Iran \\ ${ }^{6}$ Department of Orthopedic and Traumatology, Universitätsklinikum Bonn, Bonn, \\ Germany
}

Submitted: 8 March 2016

Accepted: 7 April 2016

Arch Med Sci 2017; 13, 6: 1347-1351

DOI: 10.5114/aoms.2016.59710

Copyright $\odot 2016$ Termedia \& Banach

\section{Abstract}

Introduction: The aim of this study was to facilitate and deepen the understanding of the associations of the clinical significance of PLA2G16 and $\mathrm{CDH} 11$ in patients with osteosarcoma.

Material and methods: We collected 50 paired osteosarcoma tissues and adjacent normal bone tissues and evaluated the expression of PLA2G16 and $\mathrm{CDH} 11$ by quantitavise reverse transcriptase real-time polymerase chain reaction.

Results: PLA2G16 expression was upregulated in osteosarcoma tissues when compared with adjacent normal bone tissues, and the difference was statistically significant $(4.78 \pm 0.70$ vs. $1.31 \pm 0.65$; $p<0.05)$. Our data indicated that high expression of PLA2G16 was significantly related to advanced TNM stage and metastasis or recurrence $(p<0.05)$. The expression level of $\mathrm{CDH} 11$ was lower in osteosarcoma tissues (median relative expression level \pm SD: $6.29 \pm 1.43$ ) than adjacent normal bone tissues (mean \pm SD: $13.72 \pm 3.08, p<0.05$ ). Our findings demonstrated that decreased expression of CDH11 was strongly linked to advanced TNM stage, and metastasis or recurrence $(p<0.05)$. Log-rank analysis showed that patients with high expression of PLA2G16 have shorter overall survival than those with low expression. Moreover, shorter overall survival was significantly correlated with decreased expression of $\mathrm{CDH} 11$. Multivariate Cox proportional hazards analysis showed that PLA2G16 $(p=0.028 ; \mathrm{HR}=2.621 ; 95 \% \mathrm{Cl})$ and $\mathrm{CDH} 11$ $(p=0.023 ; \mathrm{HR}=2.81 ; 95 \% \mathrm{Cl})$ expression and also metastasis or recurrence $(p=0.03 ; \mathrm{HR}=2.531 ; 95 \% \mathrm{Cl})$ were independent prognostic factors for poor overall survival of osteosarcoma patients.

Conclusions: These findings suggest that PLA2G16 and CDH11 expression can be independent prognostic factors for poor overall survival of patients with osteosarcoma.

Key words: PLA2G16 and CDH11, osteosarcoma, survival, clinical significance, expression.

\author{
Corresponding author: \\ Peyman Kaghazian \\ Department of Orthopedic \\ and Traumatology \\ Universitätsklinikum Bonn \\ Bonn, Germany \\ Phone: +49 15776917666 \\ E-mail: drpkaghazian@ \\ yahoo.de
}




\section{Introduction}

Osteosarcoma is known as a primary malignancy among children and young adults and also is linked to high morbidity. Despite treatment strategies including chemotherapy and surgery, the 5-year survival rate of primary osteosarcoma was estimated to be only $50-60 \%$ [1-5], and it is dissatisfactory for most patients with metastasis or recurrence. Therefore, it is very important to identify effective targets and new strategies in this field.

Pla2g16, also called H-REV-107, belongs to group XVI phospholipase $A_{2}$, and was reported to be expressed in most normal tissues $[6,7]$. PLA2G16 has been shown to play a role in progression and metastasis in osteosarcoma cell lines [8]. PLA2G16 has been reported to act as a class II tumor suppressive due to its function in inhibition of $\mathrm{H}$-ras-induced transformation. Moreover, decreased expression of PLA2G16 was reported in some kinds of tumor such as kidney, breast, and ovary [9-11]. On the other hand, upregulation of PLA2G16 expression has been found in rectum, colon, stomach and lung cancers, indicating that it can play an oncogenic role in mentioned tumors [12]. Cadherins are known as cell surface molecules for cell communication and signaling through catenin [13]. The association of cadherins with tumor progression has been reported in many kinds of cancer [14-16]. Over 20 types of cadherins have been identified, including $\mathrm{CDH} 11$, reduction of which has been reported to be associated with osteosarcoma metastasis [17]. However, the role of PLA2G16 and $\mathrm{CDH} 11$ in patients with osteosarcoma needs further studies. In the current study, we evaluated the clinical significance of PLA2G16 and CDH11 in patients with osteosarcoma.

\section{Material and methods}

\section{Ethics statement}

All clinical protocols in the present study were conducted in accordance with the Declaration of Helsinki and Good Clinical Practice Guidelines, and procedures were reviewed and approved by the Ethics Committees. In addition, all participating patients signed the consent forms.

\section{Patients and clinical samples}

We obtained 50 paired osteosarcoma tissues and adjacent normal bone tissues from different hospitals in Tehran, Iran between 2008 and December 2013. The tissues were obtained from surgical specimens and confirmed by pathological evaluation. Tumor tissues were grouped based on the sixth edition of the TNM classification of the
International Union against Cancer (UICC). The clinicopathological parameters are shown in Table I.

\section{RNA extraction and qRT-PCR}

In brief, Trizol reagent (Invitrogen, Carlsbad, CA) was used to extract total RNA. A High Capacity cDNA Archive Kit (Applied Biosystems, Foster City, CA) was used to carry out the reverse-transcription reactions.

Quantitavise reverse transcriptase real-time polymerase chain reaction was conducted by using TaqMan universal PCR master mix on the Applied Biosystems 7500 Real-Time PCR System (Applied Biosystems). The expression levels were quantitated using the TaqMan miRNA assay kit (Applied Biosystems) for PLA2G16 (Hs00912734_m1) and GAPDH (Hs02758991_g1) with gene-specific probes. Moreover, CDH11 expression (Hs00156438_m1) and internal control glyceraldehyde-3-phosphate dehydrogenase (Hs99999905_m1) were analyzed. Moreover, relative expression levels were evaluated with the comparative cycle threshold (CT) method.

\section{Statistical analysis}

Correlation between expression levels of genes and clinicopathological parameters were analyzed using the $\chi^{2}$ test. SPSS version 16.0 for Windows (SPSS Inc, IL, USA) software was used to evaluate all variables. Analysis of overall survival was performed using the log-rank test. Univariate and multivariate Cox proportional hazards analyses were applied to evaluate the prognostic role of PLA2G16 and CDH11. Statistical analysis was considered to be statistically significant at $p<0.05$.

\section{Results}

\section{PLA2G16 expression and its correlation with clinicopathological parameters}

The expression level of PLA2G16 was upregulated in osteosarcoma tissues when compared with adjacent normal bone tissues, and the difference was statistically significant $(4.78 \pm 0.70$ vs. $1.31 \pm 0.65$; $p<0.05$; Figure 1).

According to the median expression level, the expression levels of genes were categorized into low and high expression groups (Table I). Our results indicated that high expression of PLA2G16 was significantly correlated with advanced TNM stage and metastasis or recurrence $(p<0.05)$. No significant difference was found between PLA2G16 and other clinicopathological parameters (Table I).

\section{$\mathrm{CDH} 11$ expression and its correlation with clinicopathological parameters}

The expression level of $\mathrm{CDH} 11$ was downregulated in osteosarcoma tissues (median relative 
Table I. Correlation of PLA2G16 and CDH11 expression with clinicopathological features of osteosarcoma

\begin{tabular}{|c|c|c|c|c|c|c|c|}
\hline \multirow{2}{*}{$\begin{array}{l}\text { Clinicopathological } \\
\text { features }\end{array}$} & \multirow[t]{2}{*}{$N=50$} & \multicolumn{2}{|c|}{ Expression of PLA2G16 } & \multicolumn{2}{|c|}{ Expression of $\mathrm{CDH} 11$} & \multirow{2}{*}{$\begin{array}{l}\text { P-value of } \\
\text { PLA2G16 }\end{array}$} & \multirow{2}{*}{$\begin{array}{l}P \text {-value of } \\
\text { CDH11 }\end{array}$} \\
\hline & & Low $=15$ & High $=35$ & Low $=39$ & High $=11$ & & \\
\hline \multicolumn{6}{|l|}{ Gender: } & \multirow[t]{3}{*}{ NS } & \multirow[t]{3}{*}{ NS } \\
\hline Male & 32 & 9 & 23 & 25 & 7 & & \\
\hline Female & 18 & 6 & 12 & 14 & 4 & & \\
\hline \multicolumn{6}{|l|}{ Age [years]: } & \multirow[t]{3}{*}{ NS } & \multirow[t]{3}{*}{ NS } \\
\hline$\leq 40$ & 30 & 9 & 21 & 24 & 6 & & \\
\hline$>40$ & 20 & 6 & 14 & 15 & 5 & & \\
\hline \multicolumn{6}{|l|}{ Tumor diameter $[\mathrm{cm}]:$} & \multirow[t]{3}{*}{ NS } & \multirow[t]{3}{*}{ NS } \\
\hline$\leq 5$ & 28 & 8 & 20 & 23 & 5 & & \\
\hline$>5$ & 22 & 7 & 15 & 16 & 6 & & \\
\hline \multicolumn{6}{|l|}{ Location: } & \multirow[t]{3}{*}{ NS } & \multirow[t]{3}{*}{ NS } \\
\hline Distal & 31 & 10 & 21 & 24 & 7 & & \\
\hline Proximal & 19 & 5 & 14 & 15 & 4 & & \\
\hline \multicolumn{6}{|l|}{ Tumor grade: } & \multirow[t]{3}{*}{ NS } & \multirow[t]{3}{*}{ NS } \\
\hline Low & 27 & 8 & 19 & 22 & 5 & & \\
\hline High & 23 & 7 & 16 & 17 & 6 & & \\
\hline \multicolumn{6}{|c|}{ Metastasis or recurrence: } & \multirow[t]{3}{*}{$<0.05$} & \multirow[t]{3}{*}{$<0.05$} \\
\hline No & 27 & 12 & 15 & 19 & 8 & & \\
\hline Yes & 23 & 3 & 20 & 20 & 3 & & \\
\hline \multicolumn{6}{|l|}{ Histological type: } & \multirow[t]{5}{*}{ NS } & \multirow[t]{5}{*}{ NS } \\
\hline Osteoblastic & 20 & 8 & 12 & 18 & 2 & & \\
\hline Chondroblastic & 16 & 4 & 12 & 13 & 3 & & \\
\hline Telangiectatic & 8 & 1 & 7 & 5 & 3 & & \\
\hline Fibroblastic & 6 & 2 & 4 & 3 & 3 & & \\
\hline \multicolumn{6}{|l|}{ TNM stage: } & \multirow[t]{3}{*}{$<0.05$} & \multirow[t]{3}{*}{$<0.05$} \\
\hline$I+I I$ & 27 & 10 & 17 & 18 & 9 & & \\
\hline$I I I+I V$ & 23 & 5 & 18 & 21 & 2 & & \\
\hline
\end{tabular}

expression \pm SD: $6.29 \pm 1.43)$ compared to adjacent normal bone tissues (mean \pm SD: $13.72 \pm 3.08$, $p<0.05$; Figure 1).

We found that low expression of $\mathrm{CDH} 11$ was strongly linked to advanced TNM stage, and metastasis or recurrence $(p<0.05)$. Furthermore, no significant association was found between $\mathrm{CDH} 11$ and other clinicopathological parameters (Table I). Log-rank analysis showed that patients with high expression of PLA2G16 had shorter overall survival than those with low expression. Moreover, shorter overall survival was significantly correlated with decreased expression of $\mathrm{CDH} 11$.

\section{Correlation of expression with prognosis}

The multivariate Cox proportional hazards model analysis showed that PLA2G16 ( $p=0.028$; $\mathrm{HR}=2.621 ; 95 \% \mathrm{Cl})$ and $\mathrm{CDH} 11(p=0.023 ; \mathrm{HR}=$ $2.81 ; 95 \% \mathrm{Cl})$ expression and also metastasis or recurrence $(p=0.03 ; \mathrm{HR}=2.531 ; 95 \% \mathrm{Cl})$ were independent prognostic factors for poor overall survival of patients with osteosarcoma (Table II).

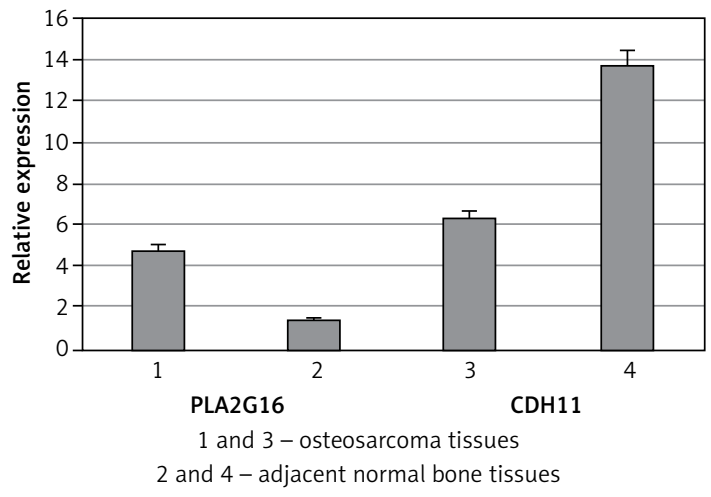

Figure 1. Expression of PLA2G16 and CDH11 was determined by quantitative real-time PCR in paired human osteosarcoma and adjacent normal tissues

\section{Discussion}

Despite treatment strategies including chemotherapy and surgery, the 5-year survival rate of primary osteosarcoma was estimated to be only $50-60 \%[1-5,15]$. Therefore, the study of osteosarcoma biomarkers is very important to identify 
Table II. Multivariate analysis of the relationship of PLA2G16 and CDH11 expression with clinicopathological features

\begin{tabular}{|lccc|}
\hline Clinicopathological characteristics & HR & 95\% Cl & $P$-value \\
\hline Age & 0.521 & $0.682-1.542$ & 0.582 \\
\hline Gender & 0.472 & $0.582-1.248$ & 0.592 \\
\hline Tumor diameter $[\mathrm{cm}]$ & 0.751 & $1.367-2.06$ & 0.52 \\
\hline Location & 1.234 & $1.213-2.158$ & 0.231 \\
\hline Metastasis or recurrence & 2.531 & $1.245-6.73$ & 0.03 \\
\hline TNM stage & 1.023 & $0.92-2.041$ & 0.326 \\
\hline Histological type & 1.01 & $0.942-1.621$ & 0.432 \\
\hline Expression of PLA2G16 & 2.621 & $1.783-6.189$ & 0.028 \\
\hline Expression of CDH11 & 2.81 & $1.117-7.126$ & 0.023 \\
\hline
\end{tabular}

effective targets and new strategies in this field. The expression level of PLA2G16 was upregulated in osteosarcoma tissues when compared with adjacent normal bone tissues, and the difference was statistically significant $(p<0.05)$. Our results indicated that high expression of PLA2G16 was significantly correlated with advanced TNM stage and metastasis or recurrence. Multivariate Cox proportional hazards model analysis showed that PLA2G16 expression and also metastasis or recurrence were independent prognostic factors for poor overall survival of patients with osteosarcoma.

PLA2G16 has been found to be involved in progression and metastasis of osteosarcoma in both mouse and human osteosarcoma cell lines [8]. The PLA2G16 marker has been accepted as a class II tumor suppressive due to its function in inhibition of H-ras-induced transformation. Low expression of the PLA2G16 gene has been found in some types of tumor such as renal, breast, and ovary [911]. On the other hand, upregulation of PLA2G16 expression has been found in rectum, colon, stomach and lung cancers, indicating that it can play an oncogenic role in the mentioned tumors [12].

A recent study demonstrated that metastatic osteosarcoma was related to PLA2G16 expression at both protein and mRNA levels when comparing osteosarcoma with and without metastasis. The mentioned study showed that negative PLA2G16 protein expression was related to higher survival rates for 3-year overall survival and metastasis-free survival than the positive expression of PLA2G16. Consistent with the results of that study, our results showed that high expression of PLA2G16 was significantly correlated with advanced TNM stage and metastasis or recurrence. Log-rank analysis showed that patients with high expression of PLA2G16 have shorter overall survival than those with low expression. Increased expression of PLA2G16 mediated by mutant $\mathrm{p} 53$ contributes to progression and metastasis of osteosarcoma [18]. It can be useful to evaluate whether p53 mutations are associated with expression of PLA2G16 in osteosarcoma.

Furthermore, it has been indicated that PLA2G16 produced free fatty acids, arachidonic acid, and lysophosphatidic acid from phosphatidylcholine [5]. Arachidonic acid can be converted by cyclooxygenase-2 (COX-2) into prostaglandin E2 (PGE2) and other prostaglandins [19] that have an important role in regulating the invasion of cells during cancer progression [20]. Moreover, COX-2 expression has been reported to be a prognostic factor in osteosarcoma lung metastases [21]. In addition, lysophosphatidic acid was demonstrated to induce cell proliferation, invasion, and migration and promote survival [22].

In the present study, the expression level of $\mathrm{CDH} 11$ was downregulated in osteosarcoma tissues compared to adjacent normal bone tissues. We found that low expression of $\mathrm{CDH} 11$ was strongly linked to advanced TNM stage, and metastasis or recurrence. Moreover, shorter overall survival was significantly correlated with decreased expression of $\mathrm{CDH} 11$. In agreement with our results, $\mathrm{CDH} 11$ reduction has been reported to be associated with osteosarcoma metastasis [17]. Previous studies indicated that the absence or decrease of $\mathrm{CDH} 11$ expression is related to metastasis in osteosarcoma and retinoblastoma [23-27]. It has been reported that low CDH11 expression contributes to tumor invasion in many kinds of tumor [16, 24, 25], and the decrease or loss of cell differentiation is related to lower expression of $\mathrm{CDH} 11$, which may contribute to the oncogenic capacity of osteosarcoma [26]. On the other hand, in agreement with our study, a previous study showed that the $\mathrm{CDH} 11$ expression level was decreased from the osteoblast to the primary cell lines and further to tumor metastases, and high expression of $\mathrm{CDH} 11$ was significantly associated with longer survival time than those with decreased expression of $\mathrm{CDH} 11$ [27]. Further studies are required to clarify the role of $\mathrm{CDH} 11$ and its involved mechanisms in osteosarcoma. 
In conclusion, PLA2G16 and $\mathrm{CDH} 11$ expression levels can be independent prognostic factors for poor overall survival of patients with osteosarcoma.

\section{Conflict of interest}

The authors declare no conflict of interest.

\section{References}

1. Tang J, Shen L, Yang Q, Zhang C. Overexpression of metadherin mediates metastasis of osteosarcoma by regulating epithelial-mesenchymal transition. Cell Prolif 2014; 47: 427-34.

2. Montanaro L, Mazzini G, Barbieri S, et al. Different effects of ribosome biogenesis inhibition on cell proliferation in retinoblastoma protein- and p53-deficient and proficient human osteosarcoma cell lines. Cell Prolif 2007; 40: 532-49.

3. Botter SM, Neri D, Fuchs B. Recent advances in osteosarcoma. Curr Opin Pharmacol 2014; 16: 15-23.

4. Marina N, Gebhardt M, Teot L. Biology and therapeutic advances for pediatric osteosarcoma. Oncologist 2004; 9: 422-41.

5. Gill J, Ahluwalia MK, Geller D, Gorlick R. New targets and approaches in osteosarcoma. Pharmacol Ther 2013; 137: 89-99.

6. Pang $X Y$, Cao J, Addington L, et al. Structure/function relationships of adipose phospholipase A2 containing a cys-his-his catalytic triad. J Biol Chem 2012; 287: 35260-74.

7. Sers C, Husmann K, Nazarenko I, et al. The class II tumour suppressor gene H-REV107-1 is a target of interferon-regulatory factor- 1 and is involved in IFNgammainduced cell death in human ovarian carcinoma cells. Oncogene 2002; 21: 2829-39.

8. Li L, Liang S, Wasylishen AR, et al. PLA2G16 promotes osteosarcoma metastasis and drug resistance via the MAPK pathway. Oncotarget 2016 Feb 25. doi: 10.18632/ oncotarget.7694.

9. Hajnal A, Klemenz R, Schafer R. Subtraction cloning of $\mathrm{H}$-rev107, a gene specifically expressed in Hras resistant fibroblasts. Oncogene 1994; 9: 479-90.

10. Husmann K, Sers C, Fietze E, Mincheva A, Lichter P, Schafer R. Transcriptional and translational downregulation of H-REV107, a class II tumour suppressor gene located on human chromosome 11q11-12. Oncogene 1998; 17: 1305-12.

11. Tawadros T, Brown MD, Hart CA, Clarke NW. Ligand-independent activation of EphA2 by arachidonic acid induces metastasis-like behaviour in prostate cancer cells. Br J Cancer 2012; 107: 1737-44.

12. Nazarenko I, Kristiansen G, Fonfara S, et al. H-REV107-1 stimulates growth in non-small cell lung carcinomas via the activation of mitogenic signaling. Am J Pathol 2006; 169: 1427-39.

13. Tomita K, van Bokhoven A, van Leenders GJ, et al. Cadherin switching in human prostate cancer progression. Cancer Res 2000; 60: 3650-4.

14. Nakamura E, Sugihara H, Bamba M, Hattori T. Dynamic alteration of the E-cadherin/catenin complex during cell differentiation and invasion of undifferentiated-type gastric carcinomas. J Pathol 2005; 2015: 349-58.

15. Pishvaian MJ, Feltes CM, Thompson P, Bussemakers MJ, Schalken JA, Byers SW. Cadherin-11 is expressed in invasive breast cancer cell lines. Cancer Res 1999; 59: 947-52.

16. Oka H, Shiozaki H, Kobayashi K, et al. Expression of E-cadherin cell adhesion molecules in human breast cancer tissues and its relationship to metastasis. Cancer Res 1993; 53: 1696-701.

17. Kashima T, Kawaguchi J, Takeshita S, et al. Anomalous cadherin expression in osteosarcoma. Possible relationships to metastasis and morphogenesis. Am J Pathol 1999; 155: 1549-55.

18. Xiong S, Tu H, Kollareddy M, et al. Pla2g16 phospholipase mediates gain-of function activities of mutant p53. Proc Natl Acad Sci U S A 2014; 111: 11145-50.

19. Duncan RE, Sarkadi-Nagy E, Jaworski K, Ahmadian M, Sul HS. Identification and functional characterization of adipose-specific phospholipase A2 (AdPLA). J Biol Chem 2008; 283: 25428-36.

20. Cao Y, Prescott SM. Many actions of cyclooxygenase-2 in cellular dynamics and in cancer. J Cell Physiol 2002; 190: 279-86.

21. Greenhough A, Smartt HJ, Moore AE, et al. The COX-2/ PGE2 pathway: key roles in the hallmarks of cancer and adaptation to the tumour microenvironment. Carcinogenesis 2009; 30: 377-86.

22. Mills GB, Moolenaar WH. The emerging role of lysophosphatidic acid in cancer. Nature Rev Cancer 2003; 3: 582-91.

23. Marchong MN, Chen D, Corson TW, et al. Minimal 16q genomic loss implicates cadherin-11 in retinoblastoma. Mol Cancer Res 2004; 2: 495-503.

24. Schipper JH, Frixen UH, Behrens J, Unger A, Jahnke K, Birchmeier W. E-cadherin expression in squamous cell carcinomas of head and neck: inverse correlation with tumor dedifferentiation and lymph node metastasis. Cancer Res 1991; 51: 6328-37.

25. Umbas R, Isaacs WB, Bringuier PP, Xue Y, Debruyne FM, Schalken JA. Relation between aberrant alpha-catenin expression and loss of E-cadherin function in prostate cancer. Int J Cancer 1997; 74: 374-7.

26. Kii I, Amizuka N, Shimomura J, Saga Y, Kudo A. Cell-cell interaction mediated by cadherin-11 directly regulates the differentiation of mesenchymal cells into the cells of the osteolineage and the chondro-lineage. J Bone Miner Res 2004; 19: 1840-9.

27. Nakajima G, Patino-Garcia A, Bruheim S, et al. CDH11 expression is associated with survival in patients with osteosarcoma. Cancer Genom Proteom 2008; 5: 37-42. 